\title{
Yiyecek ve İçecek Issletmelerinde Ozon Uygulamaları
}

\author{
Çĭ̆dem MUSTTU \\ İstanbul Aydın Üniversitesi, ABMYO, Aşçılık Programı \\ cigdemmustu@aydin.edu.tr,https://orcid.org/0000-0003-0703-6877
}

Geliş tarihi/Received: 05.09.2019

Kabul tarihi / Accepted: 16.12.2019

\section{Öz}

Yiyecek ve içecek işletmelerinde gıda güvenliği, yemeklerin lezzetinden daha fazla önem arz etmektedir. Günümüzde gıda güvenliğini sağlamak adına dezenfeksiyon işleminde kullanılan birçok yöntem bulunmaktadır. Ancak gıdanın besinsel ve duyusal özellikleri üzerinde olumsuz etkileri önlemek, son yıllarda artmış olan doğal ürün taleplerine karşılık vermek ve kimyasal koruyucu içermeyen gıdalar üretmek adına ozon uygulamaları gibi alternatif yeni yöntemler önem kazanmıştır. Ozon, sağlık açısından zararlı kalıntı bırakmayan, güçlü bakterisidal ve viridal etkiye sahip, çevre dostu ve gıda prosesleriyle uyumlu bir gıda muhafaza yöntemidir. Gıda ile temas eden yüzeylerin, ekipmanların ve içme suyunun dezenfekte edilmesinde, istenmeyen kokuların giderilmesinde, ortam havasının dezenfeksiyonunun sağlanmasında, meyve, sebze, et ve deniz ürünleri gibi gıdaların yüzeyindeki kontaminasyonun önlenmesinde ve güvenli depolamada kullanılmaktadır. Bu makalede, toplu beslenme hizmeti veren ve gıda üretimi yapan işletmelerde, gıdalarda oluşabilecek riskleri önleyerek güvenli gıda üretmek amacıyla dezenfeksiyon işleminde kullanılan ozon ve etkilerinden bahsedilmektedir.

Anahtar Kelimeler: Dezenfeksiyon, gıda güvenliği, ozon, yiyecek ve içecek işletmeleri

\section{Ozone Applications in the Food Beverage Enterprises}

\begin{abstract}
Food safety is more important than the taste of food in food and beverage enterprises. Nowadays, there are many methods used in disinfection process to ensure food safety. However, alternative new methods such as ozone applications have gained importance in order to prevent negative effects on the nutritional and sensory properties of food, to respond to the increasing demand for natural products in recent years and to produce foods that do not contain chemical preservatives. Ozone is a food preservation method that does not leave any harmful residue for health, having a strong bactericidal and viridal effect, environmentally friendly and compatible with food processes. It is used for disinfecting of drinking water, ambient air and also surfaces and equipment in contact with food, for removing unwanted odors, for preventing contamination on the surface of foods such as fruits, vegetables, meat and seafood and for safe storage. In this article, ozone used in disinfection process in order to produce safe food by preventing the risks that may occur in foods in enterprises that provide mass nutrition services and produce food and its effects are mentioned.
\end{abstract}

Keywords: Disinfection, food safety, ozone, food and beverage enterprises 


\section{GíRiş}

Yiyecekveiçecekişletmelerindegıdagüvenliği, yemeklerin lezzetinden daha fazla önem arz etmektedir. Gıdaların raf ömrünün uzatılması, besleyici değeri ve duyusal kalitesinin korunmasiyla birlikte gıda güvenliğinin sağlanması uzun yıllar boyunca gida üretimini yapılan yerlerde zor olduğu bilinen bir durumdur (Nath vd., 2014). Yiyecek ve içecek işletmelerinde, gıda güvenliğini sağlamak adına bugünün teknolojisinde gıdaların işlenmesinde kullanılan çeșitli yöntemler bulunmaktadır (Sürel, 2012). İstenmeyen mikroorganizmaların inaktive edilmesi ve ürünün raf ömrünün uzatılması amaciyla yaygın olarak kullanılan gıda işleme yöntemi olan ısıl işlem uygulaması, bu avantajlarının yanı sıra gıdanın besin ve duyusal özellikleri üzerinde olumsuz etkilere neden olmaktadır (Güleç, 2006). Bu etkiler sonucu, yiyecek ve içecek sektöründe gıda güvenliğini sağlamak adına 1s1l olmayan tekniklerin kullanımı önem kazanmaktadır (Güleç, 2006; Sağdıç, Ekici, Yetim, 2008). Ayrica son y1llarda tüketicilerin ilgisinin, işlenmemiş ya da çok az işlem görmüş, kimyasal koruyucu içermeyen gıdalara yönelik olarak arttığı, doğal ve güvenli gıdaları tercih ettiği görülmektedir. Bunların sonucu olarak da önceden koruyucu ya da dezenfektan kullanılarak güvenli hale getirilen gıda proseslerinde, alternatif yeni yöntemlerin uygulanması yaygınlaşmaya başlamıştır (Savaş, Tavşanlı, Gökgözoğlu, 2014).

Yiyecek ve içecek işletmelerinde özellikle içme suyunda oluşabilecek istenmeyen kokular, çiğ olarak tüketilen meyve-sebzeler, et ve et ürünleri ile deniz ürünlerine kontaminasyon riski ve bu ürünlerin depolama koşulları kontrol altına alınması açısından önem arz etmektedir. $\mathrm{Bu}$ makalede, toplu beslenme hizmeti veren ve gida üretimi yapan işletmelerde gidalarda oluşabilecek riskleri önleyerek güvenli gida üretmek ve bununla birlikte gıdaların besin ve duyusal özelliklerini korunmasını sağlamak amaciyla ozon kullanımı ve etkilerinden bahsedilmektedir.

\section{Dezenfeksiyon ve Dezenfeksiyon Yöntemleri}

Yiyecek ve içecek işletmeleri kaliteli ve sağlik açısından güvenli ürünler üreterek tüketicilere sunmayı amaçlamaktadır. Ancak bu ürünlere ulaşım, kaliteli hammaddenin iyi bir teknoloji ile iyi bir hijyen ve sanitasyon programının uygulanmasıyla mümkün olmaktadır. Ürünlere mikroorganizmaların bulaşması ve bunun sonucunda oluşan olumsuzlukların önlenmesinde temizlik ve dezenfeksiyon işleminin etkin bir rolü bulunmaktadır (Şenel ve Başoğlu, 2002).

Türk Gıda Kodeksi (TGK, 2005)'ne göre dezenfeksiyon; gida maddelerine ve gida ile temasta bulunan madde ve malzemelere bulaşmayı önlemek amacıyla, gıda maddesinin ve gida ile temasta bulunan madde ve malzemelerin özelliklerini etkilemeden fiziksel ve/veya kimyasal yollarla ortamdaki mikroorganizmaların arındırılması işlemi olarak belirtilmektedir.

Yiyecekveiçecekişletmelerinde dezenfeksiyon işlemlerinde; kimyasal yöntemler, buhar ve sıcak su uygulamaları, radyasyonla dezenfeksiyon yöntemleri uygulanmakta, en yaygın yöntem olarak ise kimyasal yöntemler ön plana çıkmaktadır. Bu amaçla yiyecek ve içecek işletmelerinde en sik kullanılan dezenfektanlar klor içeren dezenfektanlar (sıv1 klor, hipokloritler, inorganik kloraminlerle, klordioksitgibi), katyonik kuarterner amonyum bileşikleri (QAC), oksidan maddeler (hidrojen peroksit, ozon gibi) ve durulamaya gereksinim duyulmayan alkol bazlı dezenfektanlar (etil alkol ve izopropil alkol) olmaktadır (Şenel ve Başoğlu, 2002). 


\section{Ozon Hakkında Genel Bilgiler}

Ozon $\left(\mathrm{O}_{3}\right)$, atmosferde doğal halde bulunmasının yanı sıra günümüzde yapay olarak da üretilebilen ve serbest oksijen radikalinin moleküler oksijene ilavesiyle oluşan üç atoma sahip oksijendir (Prabha, Barma, Singh, Madan, 2015). Oda sicaklı̆̆ında gaz formunda bulunan ozonun, kaynama noktası $-111,97 \pm 0,3{ }^{\circ} \mathrm{C}$ ve erime noktas $-192,57 \pm$ 0,4 ${ }^{\circ} \mathrm{C}^{\prime}$ dir (Nath vd., 2014: 8). Gaz haldeyken mavi, sıv1 ve katı haldeyken opak mavisiyah renktedir. Suda kısmen çözünmelerinin yanı sıra keskin bir kokuya sahiptir ve düşük konsantrasyonlarda $(0,005-0,02 \mathrm{ppm})$ kolayca tespit edilebildiği bilinmektedir (Çatal ve İbanoğlu, 2010).

Ticari kullanımı olan tek doğal dezenfektan olmanın yanı sıra, oksidasyon reaksiyonu sırasında ortam sicaklık ve nemine bağlı olarak 0,5-1 saat gibi kısa bir süre içerisinde yarılanarak hammaddesi olan oksijene dönüşebilme gibi önemli bir özelliği de bulunmaktadır. Böylece, diğer dezenfektan maddelerin aksine atık madde ve yan ürün oluşturma riski taşımaması avantaj sağlayan özellikleri arasında yer almaktadır (Çağlaroğlu, 2011; Yıldız ve Yangılar, 2014).

Güçlü bir oksidan ve dezenfeksiyon maddesi olan ozonun, diğer olumlu kılan fark1 ise, alternatif farklı dezenfektanlara göre daha geniş bir spektrumda antimikrobiyel aktivite göstermesidir (Patil, Bourke, Frias, Tiwari, Cullen, 2009). Klora göre \%52 daha etkili olması gida sanayinde etkili olarak kullanılmaya başlanmasında önemli bir etken olsa da uygun şekilde kullanılmadığında ürünler üzerinde duyusal kalite kaybı gibi bazı olumsuz etkilere de neden olabilmektedir (Nath vd., 2014, s. 7; Prabha vd., 2014). Ayrica klorlama ile karşılaştıııldığında ozon işleminin, yüksek maliyetli olması ve kurulumunun nispeten daha zor olması gibi durumlar da söz konusu olabilmektedir (Uzun, 2011; Y1ldız ve Yangilar, 2014).

Ozonun gıda işlemede pratik uygulamasında karşılaşılan en önemli unsur kontrollü kullanım zorunluluğu olması ve düşük konsantrasyonlarda bile insan sağllğ açısından risk oluşturmasıdır. Amerikan Gida ve İlaç Dairesi (FDA)'ne göre sürekli soluma emniyet seviyesi 0,01-0,05 ppm aralığında iken, burun ve boğazda keskin tahriş gibi toksisite belirtileri $0,1 \mathrm{ppm}$ dozunda ortaya çıkabilmektedir. Ayrıca insan tolerans seviyesi de maksimum 1,00 ppm olarak bilinmekte ve OSHA (Occupational Safety and Health Administration) tarafından çalışma alanlarında ozon konsantrasyonlarının $0,1 \mathrm{ppm} 8$ saat/ gün olarak uygulanması uygun görülmüş, k1sa süreli uygulama yapılması durumunda (1,5 dk) konsantrasyonun 0,3 ppm olarak uygulanabileceği kabul görmüştür (Çağlaroğlu, 2011; Mahapatra, Muthukumarappan, Julson, 2005).

\section{Ozon Uygulamaları}

Ozon uygulamaları, geleneksel muhafaza yöntemlerine alternatif olarak kullanılan, sağlık açısından zararlı kalıntı bırakmayan, güçlü bakterisidal ve viridal etkiye sahip, çevre dostu ve gıda prosesleriyle uyumlu bir gıda muhafaza yöntemidir. Yiyecek ve içecek endüstrisinde son yıllarda gıdaların duyusal, besleyici ve fizikokimyasal özelliklerinin korunmasını sağlamak adına ozon uygulanması ile ilgili çalı̧̧malar önem kazanmaktadır (Prabha vd., 2014; Savaş vd., 2014).

FDA tarafindan 1997 yılında güvenli ajanlar (GRAS) statüsü kazanmış ve FDA tarafından 2001 yılında "gidalarla doğrudan temasında sakınca olmadığı" yönündeki kararla gıdalarda sıvı ve gaz halinde kullanılabilecek 
alternatif bir koruma yöntemi olarak kabul edilmiştir. Bununla birlikte sadece içme sularının dezenfeksiyonunda kullanılmasının yanı sıra gıda muhafazasının sağlanmasında kullanılmaya başlanmıştır (Savaş vd., 2014, s. 123).

Ozonun, Listeria monocytogenes, Staphylococcus aureus, Bacillus cereus, Enterococcus faecalis gibi gram pozitif bakteriler kadar Pseudomonas aeruginosa ve Yersinia enterocolitica gibi gram negatif mikroorganizmalar üzerinede etkili olmas1, özellikle yiyecek ve içecek sektöründe kullanımını avantajlı kılmaktadır (Patil vd., 2009, s. 5; Savaş vd., 2014, s, 123). Bu amaçla, gıda ile temas eden yüzeylerin ve ekipmanların yıkanmasinda ve dezenfekte edilmesinde, içme suyunun dezenfekte edilmesinde, istenmeyen kokuların giderilmesinde, meyve, sebze, et ve deniz ürünlerinin yüzeyindeki kontaminasyonun önlenmesi ve ortam havasının dezenfeksiyonunun sağlanması ile güvenli depolamada kullanılmaktadır (Prabha vd., 2014).

Meyve ve sebzeler, hasat sirasi ve sonrasinda mikroorganizma kontaminasyon riski çok yüksek olan ve herhangi bir işlem yapılmadan tüketime sunulabilen gıdalardır. Dolayısıyla yiyecek ve içecek işletmelerindeki ürün yelpazesi içerisinde ozon uygulamalarının, daha çok meyve ve sebzelerin mikrobiyal yükünün azaltılmasında uygulandığı görülmektedir (Çatal ve İbanoğlu, 2010; Nath vd., 2014). Meyve ve sebzelerde raf ömrünü etkileyen en önemli mikroorganizma grubu küfler ve mayalar olmakla birlikte toprak kaynaklı patojenler ve kirli sulardan bulaşabilen fekal kontaminantlar da bulunabilmektedir. $\mathrm{Bu}$ riskleri önlemek amaciyla ozonun, yıkama suyunun patojen kontrolünde, depo atmosferindeki patojen ve zararlıların yok edilmesinde, organik ve inorganik kalıntıların uzaklaştırılmasında kullanıldığı görülmektedir (Nath vd., 2014).

Meyve ve sebze üzerine yapılan çalışmalara bakıldığında kontrollü şartlarda uygulanan sıvı ozonun, marul (Beltran, Selma, Marin, Gil, 2005; Ölmez ve Akbaş, 2009), biber (Sasmita vd., 2018), brokoli, salatalık, elma, armut (Skog ve Chu, 2001), kereviz (Zhang, Lu, Yu, Gao, 2005), üzüm (Sarig vd., 1996), böğürtlen (Barth, Zhou, Mercier, Payne, 1995), kavun (Selma, Ibanez, Cantwell, Suslow, 2008), çilek (Thaer, D’Onghia, Ricelli, 2013) gibi taze ürünlerdeki mikrobiyal popülasyonu azalttığı ve etilen oksidasyonu ile depolanma ömrünü uzattığı görülmektedir (Nath vd., 2014). Ayrıca kuru meyve-sebzelere gaz halinde de uygulanmaktadır. İran hurması üzerine yapılan bir çalışmada toplam mezofilik bakteri, koliform, S. aureus ve maya / küf sayısında azalma olduğu bildirilmiştir (Najafi ve Khodaparast, 2009). Zorlugenç, Zorlugenç, Öztekin ve Evliya (2008) yaptığ çalışmada ise kuru incirlerde gaz ozon kullanımının aflatoksin B1'in azaltılmasında etkili olduğu rapor edilmiştir.

Sıvı gidaların dayanıklı hale getirilmesinde kullanılan termal uygulamaların besin içeriğinde değişime neden olması, meyve suyu üretiminde alternatif bir yöntem olarak ozon uygulaması çalışmalarına yöneltmiştir. Yapılan bazı çalışmalarda elma birası (Steenstrup ve Floros, 2004), portakal (Patil vd., 2009), çilek (Tiwari, O’Donnell, Patras, Brunton, Cullen, 2009a) ve bögürtlen (Tiwari, O'donnell, Muthukumarappan, Cullen, 2009b) sularındaki ozonun mikrobiyal, fizikokimyasal ve besinsel değişimleri incelenmiş ve mikroorganizmalar üzerinde önemli etkisinin olduğu belirtilmiştir. Ancak C vitamini içeriklerinin ozon ile azaldığı, antosiyanin içeren meyve sularında ise bu renk 
maddelerinin bozulduğu saptanmıştır (Cullen vd., 2010; Tiwari vd., 2009a; Tiwari vd., 2009b).

Ozonlama, mikrobiyal yükü önemli derecede azaltmanın yanı sıra özellikle baharatlarda uçucu yağların oksidasyonunu azalttığından, baharatın endüstriyel olarak işlenmesi için önerilmektedir. Zhao ve Cranston (1995) yaptığ 1 bir çalışmada, karabiberin dekontamine edilmesi için ozon kullanımının, baharatın uçucu yağ bileşenleri üzerindeki etkilerini incelemiş, uçucu yağ bileşenlerinin önemli bir kayba uğramadığını belirlemiştir. Inan, Pala ve Doymaz (2007) ise ozonun kırmızıbiberde aflatoksin B1'in detoksifikasyonuna etkisini incelemek için yaptığı çalışmada, farklı sürelerde çeşitli ozon konsantrasyonlarıyla muamele edilen kırmızıbiberlerin aflatoksin içeriğinde azalmanın olduğunu bildirmişlerdir.

Et işletmelerinde kesim hattında karkasların duşlanmasında, et ve et ürünlerinin ambalajlanmasinda ve depolanmasinda ozon kullanıldığı gibi özellikle son yıllarda et işlemenin yapıldığg alanların, zeminin ve kullanılan ekipmanların dezenfeksiyonunda ozon kullanımının yaygınlaştığı görülmektedir. Stivarius, Pohlman, McElyea ve Apple (2002), sığır eti kesim hattında dekontaminasyon için ozon kullanımının mikrobiyal yük değișimi, renk ve koku özellikleri üzerine etkilerini incelemiştir. Kesim hattında ozon kullanımı, mikrobiyal patojenlerin azalmasını sağlarken renk veya koku gibi özelliklerin de korunmasını sağlamaktadır. Ayrıca ozonlama işlemi kanatlı etlerinin muhafazasında da gaz ve sıvı formda uygulanmış ve bu konuda olumlu sonuçlar elde edilmiştir. Mercogliano, Felice, Murru, Santonicola ve Cortesi (2014) yaptığ çalışmada ise kanatlı karkaslarının depolanması sırasında ozon gazı uygulamasının biyojenik amin üretimine etkilerini değerlendirmiştir.
Ozon işleminin mikrobiyal kontaminasyonun azalmasına neden olduğu için ette biyojen amin oluşumunu azalttığı ve etin tazeliğinin korunmasında etkili olduğu görülmektedir. Bunların yanı sira ozon uygulamalarının et ve et ürünlerinde uygulanmasının ürünlerde yağ oksidasyonuna neden olması gibi dezavantaj1 da bulunmaktadır. Okayama vd. (2002), yaptığ 1 bir çalışmada sığır etleri üzerine ozonlu su, ozon buharı ve ozonlu hava uygulanmış ve yalnızca ozonlu havanın lipid oksidasyonunu önemli oranda arttırdığı, diğer ozon uygulamalarının önemli bir etki yaratmadığı saptanmıştır.

$\mathrm{Su}$ ürünleri işleme tesislerinde balıkların işlendiği yüzey ve ekipmanların temizliğinin sağlanması, ürünlerin renk, parlaklık, koku gibi kalite özelliklerinin korunmasında ve kontamine edebilecek mikroorganizmaların yok edilmesinde ozon uygulamalarının yaygın olduğu görülmektedir. Özellikle de balıkların nakliyesi ve işlenmesi sırasında tazeliğinin korunması için ozon kullanımı önem taşımaktadır (Alparslan, Baygar, Yıldız, 2012; Khadre, Yousef, Kim, 2001). Gelman, Sachs, Khanin, Drabkin ve Glatman (2005) yaptığı bir çalışmada, balıkların depolanma ömrünü uzatmak adına ozon ile ön işlem uygulanmasının raf ömrünü 12 gün arttırdığ 1 bildirilmiştir.

Yumurtanın kabuk yüzeyindeki bakteriler uygun nem ve sicaklikta yumurta içine geçebilmekte ve bu kontaminantların yüzeyden uzaklaştırılması amaciyla yumurtalar oynaylanmış bir kimyasal ile yıkanabilmekte ya da yumurtalara pastörizasyon işlemi uygulanabilmektedir. Kimyasal ile yıkama sonucu yüksek seviyede klor kullanımı, yumurtanın besin kalitesi üzerine olumsuz etki edebilmektedir. Bununla birlikte pastörizasyon işlemi ile de 1sıya direnci yüksek mikroorganizmalara yetersiz etki etmesinden 
dolayı gıda güvenliğini sağlayamamaktadır. Yumurta yüzeyinin dezenfeksiyonunu sağlamak amaciyla yapılan çalışmada, ozon uygulamalarının yumurta kabuğunda bulunan mikroorganizmalar üzerine önemli derecede etkili olduğu, duyusal ve kalite özelliklerinde herhangi olumsuz bir etki oluşturmadığı belirtilmektedir (Özbakır, 2015).

Ozon uygulamalar1 mikroorganizma popülasyonunun azaltılmasında olduğu kadar mikotoksin yıkımı ve tahıl kalitesi üzerine de başarılı sonuçlar veren, daha çok fungal bulaşmaların azaltılması için kullanılan bir fumiganttır (Demir, Elgün, Elgün, 2011; Tiwari vd., 2010). Ozon uygulamalarının tahıl kalitesi üzerindeki etkilerinin araştırıldığı çalışmalarda, yüksek ozon konsantrasyonuna uzun süre maruz kalmanın tahıl tanelerinin besin içeriğine olumsuz etkisinin bulunmadığı, mikroorganizma popülasyonlarında önemli bir azalma sağladığı ve ozonlanmış suyun yumuşak ve sert buğdayın tavlanmasında başarıyla kullanılabileceği ve belirtilmektedir (İbanoğlu, 2001; Mendez, Maier, Mason, Woloshuk, 2003). Demir vd. (2011) farklı tipteki unlara ozon uygulayarak hamur ve ekmek kalitesi üzerine etkilerini incelemiş oldukları çalışmada, ozon uygulamalarının yaş glüten miktarını az da olsa artırdığı, un rengi üzerinde oksidan madde özelliği sağlayarak daha beyaz un elde edildiğini belirlemişlerdir. Ayrıca hamur reolojisi özellikleri üzerinde olumsuz bir etkisinin olmadığı ve özellikle düşük randımanlı unlarda ekmek hacmini artırdığ 1 tespit edilmiştir.

\section{SONUÇ}

Gidalar üzerine güçlü bir oksidan ve dezenfeksiyon maddesi olan ozon, toksik olmayan parçalanma ürünlerine dönüşmekte ve oksidasyon yolu ile diğer dezenfektanlara göre daha geniş bir spektrumda antimikrobiyel aktivite göstermektedir. Yiyecek ve içecek işletmelerinde özellikle meyve ve sebzelerde mikrobiyal kirliliğin giderilmesinde ozonun kullanılıp başarılı sonuçlar elde edildiği görülmektedir. Bunların yanı sıra et ve et ürünleri, su ürünleri, yumurta, tahıl ve tahıllardan elde edilen ürünlerin işlenmesinde, gıda ile temas eden yüzey ve ekipmanlar ile içme suyunun dezenfekte edilmesinde, güvenli depolamada da kullanıldığ çalışma bulunmadığı görülmektedir.

Ozon uygulamaları mikrobiyal kalite açısından ürünler üzerinde başarılı sonuçlar sağlasa da et ve et ürünleri, süt ve süt ürünleri, tahıllar gibi yağ içeriği fazla olan gidalarda oksidasyona neden olduğundan besinsel ve duyusal özelliklerde kayba neden olmaktadır. Bunun sonucu olarak antimikrobiyal etkileri gibi avantajları ile dezavantajlarının da araştırılarak birlikte değerlendirilmesi gereği ortaya çıkmaktadır. Ayrıca ozon konsantrasyonu belli miktarı aştı̆ıında risk oluşturabildiğinden, ozon kulllanım konsantrasyonlarının sağlık açısından tehlikeli olmayacak düzeyde olması ve konrollü koşullarda kullanılması gerekmektedir.

\section{KAYNAKÇA}

Alparslan, Y., Baygar, T., Yıldız, D. (2012). Su Ürünleri İşleme Tesislerinde Ozon ve Önemi. Electronic Journal of Food Technologies, 7(3), 24-31.

Barth, M. M., Zhou, C., Mercier, J., Payne, F. A. (1995). Ozone storage effects on anthocyanin content and fungal growth in blackberries. Journal of Food Science, 60(6), 1286-1288.

Beltran, D., Selma, M. V., Marin, A., Gil, M. I. (2005). Ozonated water extends the shelf life of fresh-cut lettuce. Journal of Agriculture and Food Chemistry, 53(14), 5654-5663. 
Cullen, P. J., Valdramidis, V.P., Tiwari, B. K., Patil, S., Bourke, P., O'donnell, C. P. (2010). Ozone processing for food preservation: an overview on fruit juice treatments. Ozone: Science and Engineering, 32(3), 166-179.

Çağlaroğlu, Ç. (2011). Farklı Seviyelerde Ozon Kullanımının Erzurum İli İçme Suyunun Bazı Fiziksel, Kimyasal ve Mikrobiyolojik Özellikleri Üzerine Etkisi. Atatürk Üniversitesi, Fen Bilimleri Enstitüsü, Yüksek Lisans Tezi, Erzurum.

Çatal, H., İbanoğlu, Ş. (2010). Gıdaların Ozonlanması. Gida Teknolojileri Elektronik Dergisi, 5(3), 47-55.

Demir, M. K., Elgün, A., Elgün, M. S. (2011). Farkl1 Tip Unlara Ozon Uygulamasinın Un, Hamur ve Ekmek Kalitesi Üzerine Etkisi. G1da, 36(4), 209-216.

Gelman, A., Sachs, O., Khanin, Y., Drabkin, V., Glatman, L. (2005). Effect of ozone pretreatment on fish storage life at low temperatures. Journal of Food Protection, 68(4), 778-784.

Güleç, H. A. (2006). Modern Gıda Muhafazasinda Vurgulu Elektrik Alan ve Ultrason Uygulamaları. Türkiye 9. Gıda Kongresi, 24-26 May1s 2006, Bolu (Bildiri kitab1 s.73).

Ibanoglu, S. (2001). Influence of tempering with ozonated water on the selected properties of wheat flour. Journal of Food Engineering, 48(4), 345-350.

Inan, F., Pala, M. Doymaz, M. (2007). Use of ozone in detoxification of aflatoxin B1 in red pepper. Journal of Stored Products Research, 43(4), 425-429.

Khadre, M. A., Yousef, A. E., Kim, J. G. (2001). Microbiological aspects of ozone applications in food: A review. Journal of Food Science, 66(9), 1242-1252.
Mahapatra, A. K., Muthukumarappan, K., Julson, J. L. (2005). Applications of ozone, bacteriocins and irradiation in food processing: a review. Critical Reviews in Food Science and Nutrition, 45(6), 447-461.

Mendez, F., Maier, D. E., Mason, L. J., Woloshuk, C. P. (2003). Penetration of ozone into coloumns of stored grains and effects on chemical composition and processing performance. Journal of Stored Products Research, 39(1), 33-44.

Mercogliano, R., Felice, A. D., Murru, N., Santonicola, S., Cortesi, M. L. (2014). Ozone decontamination of poultry meat and biogenic amines as quality index. Food Processing and Technology, 5(3), 305-310.

Najafi, M. B. H., Khodaparast, M. H. K. (2009). Efficacy of ozone to reduce microbial populations in date fruits. Food Control, 20(1), 27-30.

Nath, A., Mukhim, K., Swer, T., Dutta, D., Verma, N., Deka, B. C. Gangwar, B. (2014). Gıda İşleme ve Paketlemede Ozon Uygulaması Üzerine Bir İnceleme. Gıda Ürünleri Geliştirme ve Paketleme Dergisi, 1(2), 7-21.

Okayama, T., Iwanaga, S., Mitsui, Y., Isayama, T., Houzouji, T., Muguruma, M. (2002). Effect of ozone treatment on metmyoglobin formation and lipid oxidation on beef, 48 th ICoMST, 25-30 Ağustos 2002, Rome (Abstracts book, s.192).

Ölmez, H. Akbaş, M. Y. (2009). Optimization of ozone treatment of fresh-cut green leaf lettuce. Journal Food Engineering, 90(4), 487494.

Özbakır, S. (2015). Yumurta yüzeyinin dezenfeksiyonunda ozon ve ultrasonikasyon teknolojilerinin kullanılması. Abant İzzet Baysal Üniversitesi, Fen Bilimleri Enstitüsü, Yüksek Lisans Tezi, Bolu. 
Patil, S., Bourke, P., Frias, J. M., Tiwari, B. K., Cullen, P. J. (2009). Inactivation of Escherichia coli in orange juice using ozone. Innovative Food Science and Emerging Technologies, 10(4), 551-557.

Prabha, V., Barma, R. D., Singh, R., Madan, A. (2015). Ozone technology in food processing: A review. Trends in Biosciences, 8(16), 4031-4047.

Sağdıç, O., Ekici, L., Yetim, H. (2008). Gıdaların muhafazasında yeni mikrobiyal inaktivasyon metotları. Türkiye 10. Gıda Kongresi, 21-23 May1s 2008, Erzurum. (Bildiri kitab1 s.949).

Sarig, P., Zahavi, T., Zutkhi, Y., Yannai, S., Lisker, N., Ben-Arie, R. (1996). Ozone for control of post-harvest decay of table grapes caused by Rhizopusstolonifer. Physiological and Molecular Plant Pathology, 48(6), 403415.

Sasmita, E., Susan, A. I., Yulianto, E., Restiwijaya, M., Kinandana, A. W., Arianto, F., Nur, M. (2018). Effects of ozonewashing in a series of ozonation methods for inhibition of total microbial growth in some varieties of chili (Capsicum annuum L.). In IOP Conference Series: Materials Science and Engineering, 434(1), 12020-12031.

Savaş, E., Tavşanlı, H., Gökgözoğlu, İ. (2014). Gıda Endüstrisinde Ozon Uygulamaları. Türk Tarım-G1da Bilim ve Teknoloji Dergisi, 2(3), 122-127.

Selma, M. V., Ibanez, A. M., Cantwell, M., Suslow, T. (2008). Reduction by gaseous ozone of Salmonella and microbial flora associated with fresh-cut cantaloupe. Food Microbiology, 25(4), 558-565.
Skog, L. J. Chu, C. L. (2001). Effect of ozone on qualities of fruits and vegetables in cold storage. Canadian Journal of Plant Science, 81(4), 773-778.

Steenstrup, L. D., Floros, J. D. (2004). Inactivation of E. coli 0157:H7 in Apple Cider by Ozone at Various Temperatures and Concentrations. Journal of Food Processing and Preservation, 28(2), 103-116.

Stivarius, M. R., Pohlman, F. W., McElyea, K. S., Apple, J. K. (2002). Microbial, instrumental color andodor characteristics of ground beaf produced from beef trimmings treated with ozone or chlorine dioxide. Meat Science, 60(3), 299-305.

Sürel, C. (2012). Bazı Sebzelerde Dondurma Ve Donmuş Muhafaza Sürecinde Askorbik Asit, Beta Karoten Ve Tekstürel Değişimlerin İncelenmesi. Pamukkale Üniversitesi, Fen Bilimleri Enstitüsü, Yüksek Lisans Tezi, Denizli.

Şenel, Y., Başoğlu, F. (2002). G1da işletmelerinde kullanılan bazı dezenfektanların mikroorganizmalar üzerine etkileri. Uludağ Üniversitesi Zirat Fakültesi Dergisi, 16, 105 115.

Thaer, Y., D'Onghia, A. M., Ricelli, A. (2013). The use of ozone in strawberry post harvest conservation. IOBC-WPRS Bulletin, 86, 143-148.

Tiwari, B. K., Brennan, C. S., Curran, T., Gallagher, E., Cullen, P. J., O'Donnell, C. P. (2010). Application of ozone in grain processing. Journal of Cereal Science, 51(3), 248-255. 
Tiwari, B. K., O'donnell, C. P., Patras, A., Brunton, N., Cullen, P. J. (2009a). Effect of ozone processing on anthocyanins and ascorbic acid degradation of strawberry juice. Food Chemistry, 113(4), 1119-1126.

Tiwari, B. K., O'donnell, C. P., Muthukumarappan, K., Cullen, P.J.(2009b). Anthocyanin and colour degradation in ozone treated blackberry juice. Innovative Food Science and Emerging Technologies, 10(1), 70-75.

Türk Gıda Kodeksi Gıda ve Gıda ile Temasta Bulunan Madde ve Malzemelerin Piyasa Gözetimi, Kontrolü ve Denetimi ile İşyeri Sorumluluklarına Dair Yönetmelik (2005, 30 Mart). Resmî Gazete (Sayı: 25771). https://www.resmigazete.gov.tr/ eskiler/2005/03/20050330-9.htm

Uzun S. (2011). Su Kalitesinin İyileştirilmesinde Ozon Kullanımı ve Kimyasal Etkileri. Türk Hijyen ve Deneysel Biyoloji Dergisi, 68 (2), 105-113.
Yıldız, P. O., Yangılar, F. (2014). Ozon ve Gıda Endüstrisinde Kullanım Alanları. Bitlis Eren Üniversitesi Fen Bilimleri Dergisi, 3(1), 94-101.

Zhang, L., Lu, Z., Yu, Z., Gao, X. (2005). Preservation of fresh-cut celery by treatment of ozonated water. Food Control, 16(3), 279283.

Zhao, J., Cranston, P. M. (1995). Microbial decontamination of black pepperby ozone and the effect of the treatment on volatile oil constituents of the spice. Journal of Science of Food and Agriculture, 68(1), 11-18.

Zorlugenç, B., Zorlugenç, F. K., Öztekin, S., Evliya, I. B. (2008). The influence of gaseous ozone and ozonated water on microbial flora and degradation of aflatoxin B1 in dried figs. Food and Chemical Toxicology, 46(12), 35933597. 